\title{
Maximum Observed Excretion Rate
}

National Cancer Institute

\section{Source}

National Cancer Institute. Maximum Observed Excretion Rate. NCI Thesaurus. Code C85699.

The maximum observed excretion rate. 